\title{
One- and two-photon activated phototoxicity of conjugated porphyrin dimers with high two-photon absorption cross-sections $\uparrow$
}

\author{
Emma Dahlstedt, ${ }^{a}$ Hazel A. Collins, ${ }^{a}$ Milan Balaz, ${ }^{a}$ Marina K. Kuimova, ${ }^{b}$ Mamta Khurana, ${ }^{c}$ Brian C. \\ Wilson, ${ }^{c}$ David Phillips ${ }^{* b}$ and Harry L. Anderson $* a$
}

\author{
s Receipt/Acceptance Data [DO NOT ALTER/DELETE THIS TEXT] \\ Publication data [DO NOT ALTER/DELETE THIS TEXT] \\ DOI: 10.1039/b000000x [DO NOT ALTER/DELETE THIS TEXT]
}

Two-photon excited photodynamic therapy (PDT) has the potential to provide a highly targeted treatment for neoplastic diseases, as excitation can be pin-pointed to small volumes at the laser

10 focus. In addition, two-photon PDT offers deeper penetration into mammalian tissue due to the longer wavelength of irradiation. Here we report the one-photon and two-photon excited PDT results for a collection of conjugated porphyrin dimers with high two-photon absorption crosssections. These dimers demonstrate high one-photon PDT efficacy against a human ovarian adenocarcinoma cell line (SK-OV-3) and exhibit no significant dark-toxicity at concentrations of

15 up to $20 \mu \mathrm{M}$. Their one-photon excited PDT efficiencies, following irradiation at $657 \mathrm{~nm}$, approach that of Visudyne ${ }^{\mathbb{B}}$, a drug used clinically for PDT. We investigated and optimised the effect of the photosensitiser concentration, incubation time and the light dose on the PDT efficacy of these dimers. These studies led to the selection of $\mathbf{P}_{\mathbf{2}} \mathbf{C}_{\mathbf{2}}$-NMeI as the most effective porphyrin dimer. We have demonstrated that $\mathbf{P}_{\mathbf{2}} \mathbf{C}_{\mathbf{2}}$-NMeI undergoes a two-photon activated process following excitation 20 at $920 \mathrm{~nm}(3.6-6.8 \mathrm{~mW}, 300 \mathrm{fs}, 90 \mathrm{MHz})$ and compared it to Visudyne ${ }^{\circledR}$. We conclude that the in vitro two-photon PDT efficacy of $\mathbf{P}_{\mathbf{2}} \mathbf{C}_{\mathbf{2}}$-NMeI is about twice that of Visudyne ${ }^{\circledR}$. This result highlights the potential of this series of porphyrin dimers for two-photon PDT.

\section{Introduction}

${ }_{25}$ Photodynamic therapy (PDT) uses a light-activated drug, known as a photosensitiser, to treat neoplastic diseases. ${ }^{1-8}$ The treatment is relatively benign and gives good cosmetic outcomes. One of the major drawbacks is that the drugs are excited by visible light which cannot penetrate deeply into 30 tissues. $^{9-13}$ Furthermore, the majority of commercial photosensitisers show little discrimination in uptake in diseased cells vs. normal healthy tissue. ${ }^{14}$ Both of these limitations may be reduced by exciting the photosensitiser via simultaneous two-photon absorption (TPA). Not only does 35 two-photon excitation require near-IR light which is capable of travelling further through tissues than visible light, but also the nonlinear process restricts absorption to the laser focus. ${ }^{15}$, ${ }^{16}$ Thus greater treatment depths and highly-selective targeting may be achieved by two-photon PDT.

40 The efficiency by which a photosensitiser undergoes twophoton absorption is quantified by its TPA cross-section $(\delta)$, measured in Göppert-Mayer units $\left(1 \mathrm{GM}=10^{-50} \mathrm{~cm}^{4} \mathrm{~s}\right.$ photon $^{-1}$ molecule $\left.^{-1}\right)$. The TPA cross-sections of existing

\footnotetext{
${ }^{a}$ Department of Chemistry, University of Oxford, Chemistry Research Laboratory, Mansfield Road, Oxford, OXI 3TA, UK. Fax: +44 1865 285002; Tel: +44 1865 275744; E-mail: harry.anderson@chem.ox.ac.uk.

${ }^{b}$ Chemistry Department, Imperial College London, Exhibition Road, London,SW7 2AZ,UK.E-mail: d.phillips@imperial.ac.uk.

c Department of Biophysics and BioImaging, Ontario Cancer Institute, University of Toronto, 610 University Ave, $\mathrm{Rm} 7-417$, Toronto, ON M5G2M9, Canada. Fax: +416946 6529; Tel: +416946 29524; E-mail: wilson@uhnres.utoronto.ca

$\uparrow$ Electronic Supplementary Information (ESI) available: additional phototoxicity data. See http://dx.doi.org/10.1039/b000000x/
}

photosensitisers are in the order of $1-100 \mathrm{GM}$ which is too 45 small to be clinically useful. ${ }^{17}$ Two-photon PDT has been demonstrated in ovo by Cramb and co-workers; blood vessels in the chorioallantoic membrane were occluded by two-photon activation of the commercial photosensitiser Visudyne ${ }^{\circledR} .^{18}$ However, the low TPA cross-section of the drug necessitated 50 a high light intensity which was close to the photodamage threshold. ${ }^{19}$ Thus phototherapeutic compounds with higher TPA cross-sections are needed to expand the clinical applications of two-photon excited PDT.

With the adoption of multi-photon imaging and micro${ }_{55}$ fabrication as standard techniques, ${ }^{20,21}$ interest in designing chromophores with large two-photon cross-sections has expanded rapidly. ${ }^{22-26}$ Recently, focus has turned to compounds for two-photon excited PDT, although only a few of these have shown in vitro activity and few in vivo studies 60 have been published. ${ }^{27-33}$

We have recently reported a family of ionic conjugated porphyrin dimers with peak TPA cross-sections as large as 17,000 GM (Fig. 1). ${ }^{34}$ Since these molecules exhibit strong linear absorption at $700-800 \mathrm{~nm}$, they are also promising for ${ }_{65}$ long wavelength excitation one-photon PDT. This work led to the first demonstration of in vivo two-photon PDT using a photosensitiser specifically designed for efficient multiphoton excitation. ${ }^{34}$ In this sequence of papers, we describe the adaptation of the hydrophobic porphyrin dimer structure ${ }^{35}$ 70 to create drugs with excellent photophysical properties for PDT and which accumulate efficiently in human ovarian cancer cells $(\mathrm{SK}-\mathrm{OV}-3){ }^{36}$ 
Here we present a systematic study of the in vitro one- and two-photon phototoxic properties of the cationic $\left(\mathbf{P}_{\mathbf{2}}-\mathbf{N M e I}\right.$,

${ }_{75} \mathbf{P}_{2} \mathbf{C}_{2}$-NMeI and $\mathbf{P}_{2}$-NMe 3 OAc) and anionic $\left(\mathbf{P}_{2}-\mathbf{S O}_{3} \mathbf{N H}_{4}\right.$ and $\mathbf{P}_{2} \mathbf{C}_{2}-\mathbf{C O}_{2} \mathbf{N H}_{4}$ ) porphyrin dimers (Fig. 1).

\section{Results and Discussion}

The phototoxicity of a compound depends on 1) the extinction coefficient at the activation wavelength, 2) the quantum yield 80 of singlet oxygen generation $\left(\phi_{\Delta}\right), 3$ ) the stability of the compound in the biological environment, and 4) the intracellular localisation of the photosensitiser i.e. the ability of the compound to target vulnerable organelles. All four factors contribute to the PDT efficiency of a photosensitiser.

${ }_{85}$ As reported previously, ${ }^{36}$ fluorescence imaging shows that the ionic porphyrin dimers, $\mathbf{P}_{\mathbf{2}}$-NMeI, $\mathbf{P}_{\mathbf{2}} \mathbf{C}_{\mathbf{2}}$-NMeI, $\mathbf{P}_{2}$ $\mathbf{N M e}_{3} \mathrm{OAc}, \quad \mathbf{P}_{\mathbf{2}}-\mathbf{S O}_{3} \mathbf{N H}_{4}$ and $\mathbf{P}_{2} \mathbf{C}_{\mathbf{2}}-\mathbf{C O}_{2} \mathbf{N H}_{4}$, accumulate inside human ovarian adenocarcinoma epithelial cells (SKOV-3). The dimers exhibit punctate fluorescence in the 90 cytoplasm, and they have significant singlet oxygen yields in pure water $\left(\phi_{\Delta}=0.1-0.6\right),{ }^{36}$ despite aggregation. These singlet oxygen production efficiencies are comparable to those of clinical photosensitisers. ${ }^{37}$ Moreover, the singlet oxygen yields are substantially higher in methanol $\left(\phi_{\Delta}=0.5-0.9\right)$, so 95 the in vivo singlet oxygen yields should also be high, since the dimers are likely to be disaggregated in the hydrophobic compartments of cells, where they are bound to proteins or lipids.

The porphyrin dimers exhibit intense absorption in the red 100 and near-IR region $(600-850 \mathrm{~nm})$, Fig. 1 . The closely related dimers, $\mathbf{P}_{\mathbf{2}}$-NMeI, $\mathbf{P}_{\mathbf{2}}$-NMe $\mathbf{N} \mathbf{O A c}$ and $\mathbf{P}_{\mathbf{2}}-\mathbf{S} \mathbf{S}_{\mathbf{3}} \mathbf{N H}_{4}$, have their longest wavelength absorption maxima at $705-712 \mathrm{~nm}, c a$ $62,000 \mathrm{M}^{-1} \mathrm{~cm}^{-1}$. The extinction coefficients of the extended $\pi$-conjugated dimers $\mathbf{P}_{\mathbf{2}} \mathbf{C}_{\mathbf{2}}-\mathbf{C O}_{\mathbf{2}} \mathbf{N H}_{\mathbf{4}}$ and $\mathbf{P}_{\mathbf{2}} \mathbf{C}_{\mathbf{2}}$ - $\mathbf{N M e I}$ are even 105 greater, close to $120,000 \mathrm{M}^{-1} \mathrm{~cm}^{-1}$ at $746 \mathrm{~nm}$ and $769 \mathrm{~nm}$ respectively. In this respect, the dimers offer considerable improvement over the majority of commercial and clinicallyused photosensitisers. For example, the longest wavelength absorption maximum is $38,000 \mathrm{M}^{-1} \mathrm{~cm}^{-1}$ at $690 \mathrm{~nm}$ for

110 verteporfin (Visudyne ${ }^{\circledR}$ ), 42,000 $\mathrm{M}^{-1} \mathrm{~cm}^{-1}$ at $732 \mathrm{~nm}$ for lutetium texaphyrin $\left(\operatorname{Lutex}^{\circledR}\right)^{38}$ and $109,000 \mathrm{M}^{-1} \mathrm{~cm}^{-1}$ at 763 $\mathrm{nm}$ for Tookad ${ }^{\circledR}$. 39

The absorption of the photosensitisers at $657 \mathrm{~nm}$ (the emission peak of the light emitting diode, LED, light source 115 used in this study) is of primary importance for the onephoton PDT experiments reported here. The absorption spectra of the three dimers $\mathbf{P}_{\mathbf{2}}$-NMeI, $\mathbf{P}_{\mathbf{2}}-\mathbf{N M e} \mathbf{O} \mathbf{O A c}$ and $\mathbf{P}_{\mathbf{2}}$ $\mathbf{S O}_{3} \mathbf{N H}_{4}$ overlap most efficiently with the LED emission, their extinction coefficients are approximately $36,000 \mathrm{M}^{-1} \mathrm{~cm}^{-}$ ${ }_{120}^{1}{ }^{1}$ at $657 \mathrm{~nm}$, compared to 25,000 and $22,000 \mathrm{M}^{-1} \mathrm{~cm}^{-1}$ for $\mathbf{P}_{2} \mathbf{C}_{\mathbf{2}}$-NMeI and $\mathbf{P}_{2} \mathbf{C}_{\mathbf{2}}-\mathbf{C O}_{\mathbf{2}} \mathbf{N H}_{\mathbf{4}}$ respectively (Fig. 1). The absorption of the control photosensitiser verteporfin at $657 \mathrm{~nm}$ is weak compared to the dimers; its extinction coefficient is only $4500 \mathrm{M}^{-1} \mathrm{~cm}^{-1}$ at $657 \mathrm{~nm}$.

125
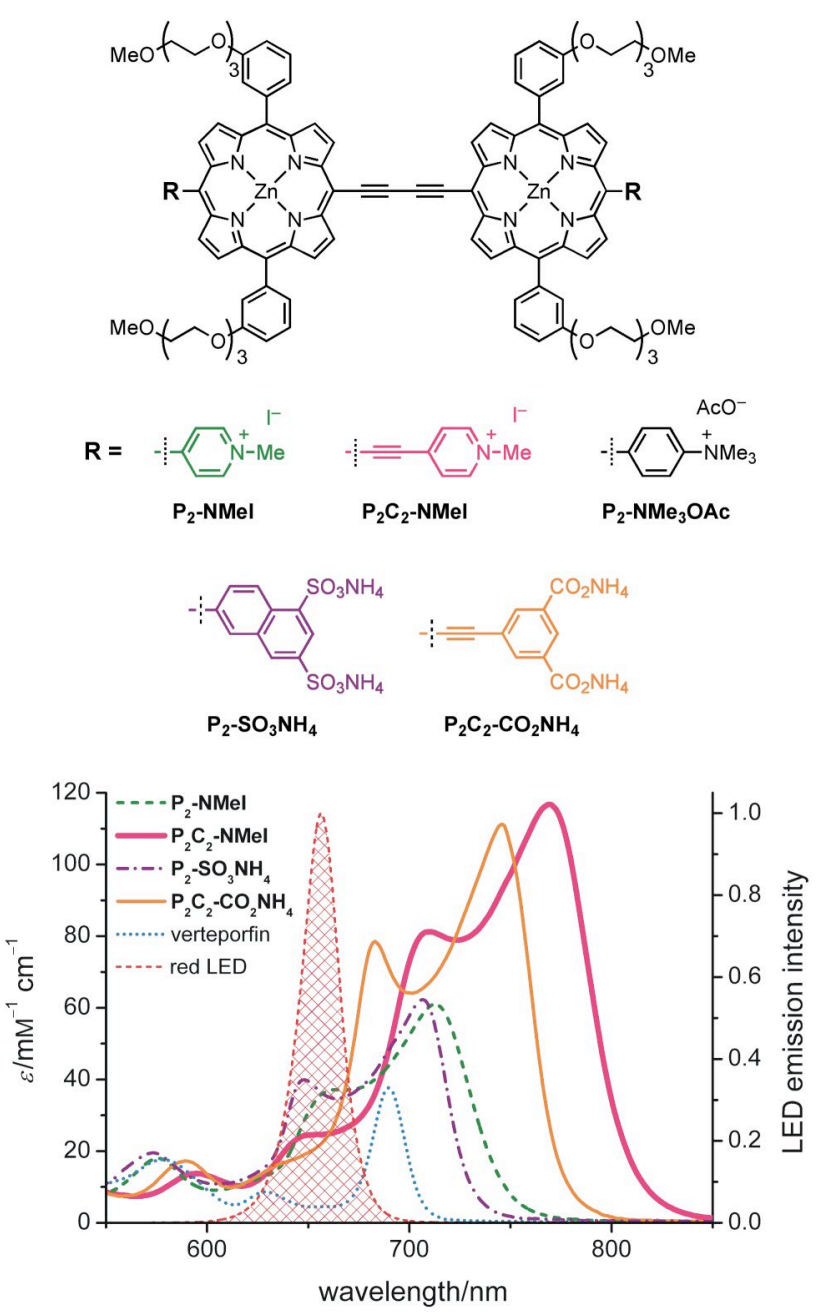

Fig. 1 Structures of the conjugated porphyrin dimers and their linear absorption spectra, shown together with that of the commercial drug verteporfin (Visudyne), measured in DMF with $1 \%$ pyridine. Included for comparison is the Gaussian (FWHM $=22 \mathrm{~nm}$ ) emission profile of the red LEDs used for the one-photon excited PDT experiments.

\section{In vitro one-photon PDT}

There is no single standard method for measuring in vitro 130 phototoxicity because of the large number of variables relating to the drug, light dose and target disease. In this study we used the adherent human epithelial ovarian adenocarcinoma cell line, SK-OV-3, grown in multiwell plates. These cells were selected since they are easy to 135 maintain as a uniform monolayer which facilitates two-photon irradiation. Lasers are the most common light sources for PDT as they can deliver focused intense monochromatic light, although they may be replaced by cheap, powerful ( $>1 \mathrm{~W}$ ) LEDs. ${ }^{40}$ There are many methods for measuring cell survival 140 after PDT in vitro. Cell death may be quantified by measuring enzyme activity, ${ }^{41}$ membrane permeability ${ }^{42}$ or redox potentials. $^{43}$

We used a purpose-built array of $657 \mathrm{~nm}$ LEDs (full width at half maximum $=22 \mathrm{~nm})$ for the one-photon PDT 145 experiments, as shown in Fig. 2 (emission spectrum in Fig. 1).

This allowed us to rapidly and reproducibly screen the compounds. The output of the LEDs $(3.2 \mathrm{~mW})$ was measured 
to be constant over a period of more than 4 hours and they were aligned directly under the sample wells $\left(0.34 \mathrm{~cm}^{2}\right)$ to 150 achieve uniform irradiation of the cells $\left(9.4 \mathrm{~mW} \mathrm{~cm}^{-2}\right)$. The cell viability was measured 48 hours after irradiation using a colourimetric proliferation assay (CellTiter $96^{\circledR}$ AQueous One solution cell proliferation assay). The 48 hour delay was sufficient to account for both apoptotic and necrotic 155 mechanisms of cell death. Exposure to the red LED light for one hour in the absence of photosensitiser had no measurable effect on cell survival.

In preliminary experiments, blue light from $470 \mathrm{~nm}$ LEDs (FWHM $=34 \mathrm{~nm}, 1.7 \mathrm{~mW}, 5.0 \mathrm{~mW} \mathrm{~cm}{ }^{-2}$ ) was also tested. 160 However, exposure to this light for more than 5 minutes reduced the viability of SK-OV-3 cells, even in the absence of a photosensitiser, Fig. S1, ESI. Blue light has been reported to be inherently mutagenic and is less effective for clinical PDT, as it is absorbed by endogenous chromophores and is strongly 165 scattered by live tissue (resulting in lower penetration depth). ${ }^{44,45}$ Therefore red light $(657 \mathrm{~nm})$ was used throughout this study.

For a given sensitiser the following parameters can be optimised to maximise the PDT effect: 1) the incubation time

170 prior to treatment, 2) the photosensitiser concentration, and 3) the light dose. We tested and optimised all three parameters for the family of porphyrin dimers shown in Fig. 1.

\section{Incubation time-dependent phototoxicity of the dimers}

The porphyrin dimers have limited solubility in water, as 175 discussed previously. ${ }^{35,36}$ Hence they were dissolved in DMSO (dimethyl sulfoxide), as $1.0 \mathrm{~mm}$ stock solutions, and then diluted in the culture medium (Dulbecco's Modified Eagle's Medium, DMEM) to the required concentration. The dimer uptake in SK-OV-3 cells was monitored by confocal

180 fluorescence microscopy, as reported earlier. ${ }^{36}$ In the previous study, we reported the the mean intracellular fluorescence intensity, while here we compare the influence of the incubation time on the PDT efficiency.

It is important that a photosensitiser is not significantly 185 dark-toxic, i.e. it should be harmless in the absence of light.

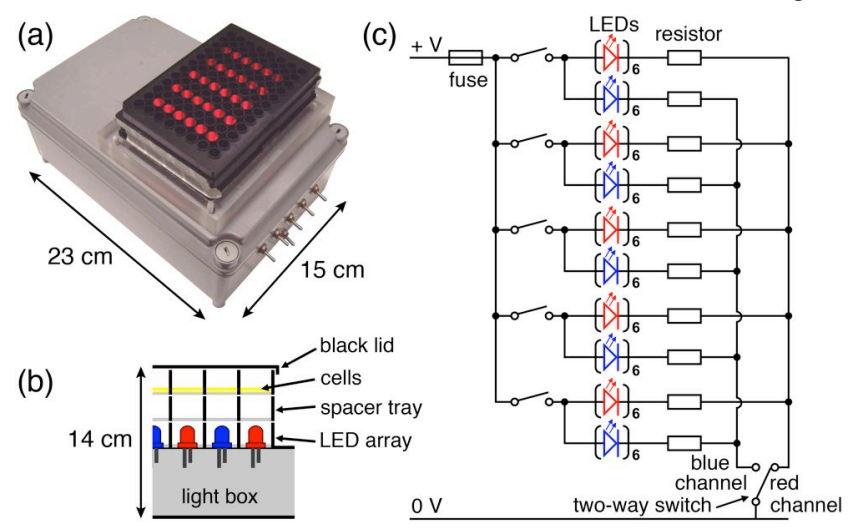

Fig. 2 Experimental setup for one-photon irradiation: (a) LED array with flat-bottomed 96-well plates placed on top. (b) cross section, (c) circuit diagram for the light box. The LED array runs on a $24 \mathrm{~V}$ rechargeable battery. The resistors for the red channels $(680 \Omega)$ and blue channels (255 $\Omega$ ) give a current of $20 \mathrm{~mA}$ for each row of six LEDs. The light intensities in the cell wells were 9.4 and $5.0 \mathrm{~mW} \mathrm{~cm}^{-2}$ respectively for the red (657 $\mathrm{nm})$ and blue (470 $\mathrm{nm})$ LEDs.

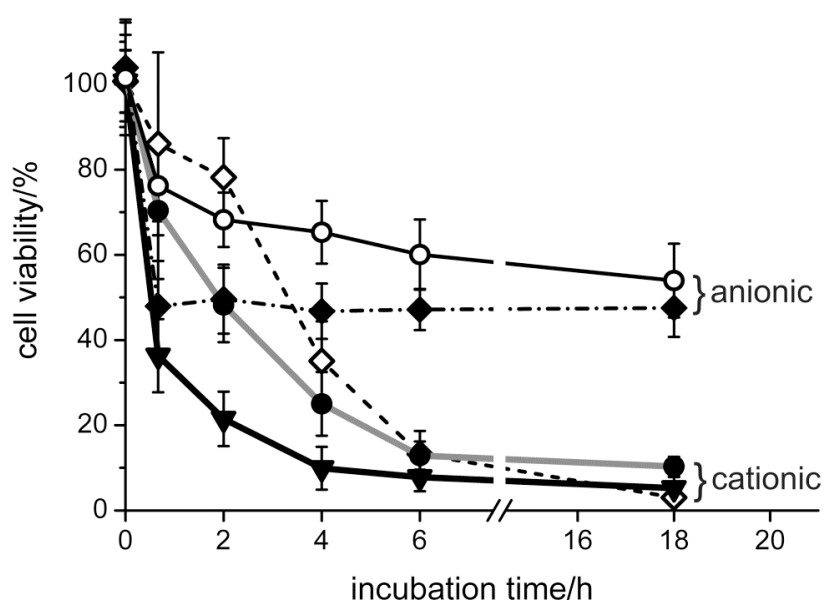

Fig. 3 Phototoxic effect of the porphyrin dimers on the viability of SKOV-3 cells versus incubation time: $\mathbf{P}_{2}$-NMeI $\left(\diamond\right.$ open diamond ), $\mathbf{P}_{2} \mathbf{C}_{2}$ $\mathbf{N M e I}\left(\boldsymbol{\nabla}\right.$ black triangle) and $\mathbf{P}_{2}-\mathbf{N M e}_{3} \mathbf{O A c}$ ( black circle), $\mathbf{P}_{2}-\mathbf{S O}_{3} \mathbf{N H}_{4}$ ( $\checkmark$ black diamond) and $\mathbf{P}_{2} \mathbf{C}_{2}-\mathbf{C O}_{2} \mathbf{N H}_{4}$ ( $\mathrm{O}$ open circle). The cells were incubated with the respective photosensitiser for various times before light exposure with $657 \mathrm{~nm}, 9.4 \mathrm{~mW} \mathrm{~cm}^{-2}$. The light dose for the cationic dimers was $10 \mathrm{~min}\left(5.6 \mathrm{~J} \mathrm{~cm}^{-2}\right)$ whereas it was $40 \mathrm{~min}\left(23 \mathrm{~J} \mathrm{~cm}^{-2}\right)$ for the anionic dimers. Cell viability percentage is calculated relative to control cells that had been administered the same light dose without drug. The error bars denote one standard deviation from 5 replicates. For additional data see Fig. S2-S6, ESI.

The porphyrin dimers demonstrated insignificant dark cytotoxicity when cells were incubated in $10 \mu \mathrm{M}$ solutions for up to 18 hours (see the following section). Promisingly, all the dimers induced a significant PDT effect when irradiated with 190 the $657 \mathrm{~nm}$ LED light. With an irradiation time of 10 minutes the three cationic dimers $\mathbf{P}_{2}$-NMeI, $\quad \mathbf{P}_{\mathbf{2}} \mathbf{C}_{\mathbf{2}}$-NMeI and $\mathbf{P}_{\mathbf{2}}-\mathrm{NMe}_{\mathbf{3}} \mathrm{OAc}$, showed a gradual increase in PDT effect with increasing incubation time (Fig. 3). From the graph in Fig. 3 it can be seen that, under the conditions used (10 min. 195 irradiation), $\mathbf{P}_{\mathbf{2}} \mathbf{C}_{\mathbf{2}}$-NMeI kills $50 \%$ of the cells with an incubation time of only 30 minutes, whereas $\mathbf{P}_{2}-\mathbf{N M e}_{3} \mathbf{O A c}$ and $\mathbf{P}_{\mathbf{2}}$-NMeI need around 2.0 and 3.5 hours respectively. On the other hand, the PDT effect of the two anionic dimers $\mathbf{P}_{\mathbf{2}}-\mathbf{S O}_{\mathbf{3}} \mathbf{N H}_{\mathbf{4}}$ and $\mathbf{P}_{\mathbf{2}} \mathbf{C}_{\mathbf{2}}-\mathbf{C O}_{\mathbf{2}} \mathbf{N H}_{\mathbf{4}}$, reaches a plateau with 2 200 hours incubation and the maximal achieved PDT effect is less than with the cationic dimers (even though a longer irradiation time of 40 minutes was used for the anionic dimers compared to $10 \mathrm{~min}$ for cationic dimers). Of the two anionic dimers, $\mathbf{P}_{\mathbf{2}^{-}}$ $\mathbf{S O}_{3} \mathbf{N H}_{4}$ achieves a greater PDT effect with shorter incubation 205 times; its maximum cell kill is around $50 \%$ after 30 minutes, whereas $\mathbf{P}_{2} \mathbf{C}_{2}-\mathbf{C O}_{2} \mathbf{N H}_{4}$ requires 18 hours incubation to reduce the cell viability by only $43 \pm 8 \%$. These trends correspond closely to those reported from the fluorescence microscopy experiments. ${ }^{36}$ That study found that the anionic dimer $\mathbf{P}_{2^{-}}$ ${ }_{210} \mathbf{S O}_{3} \mathbf{N H}_{4}$ showed rapid saturation of intracellular emission (within 2 hours), while the cationic dimers required 5-10 hours incubation to achieve their maximal intracellular fluorescence, and appeared to accumulate in the cells at a higher concentration. ${ }^{36}$

215 Since the cationic dimers appeared to be the more promising photosensitisers, the two anionic dimers were not investigated further at this stage. 

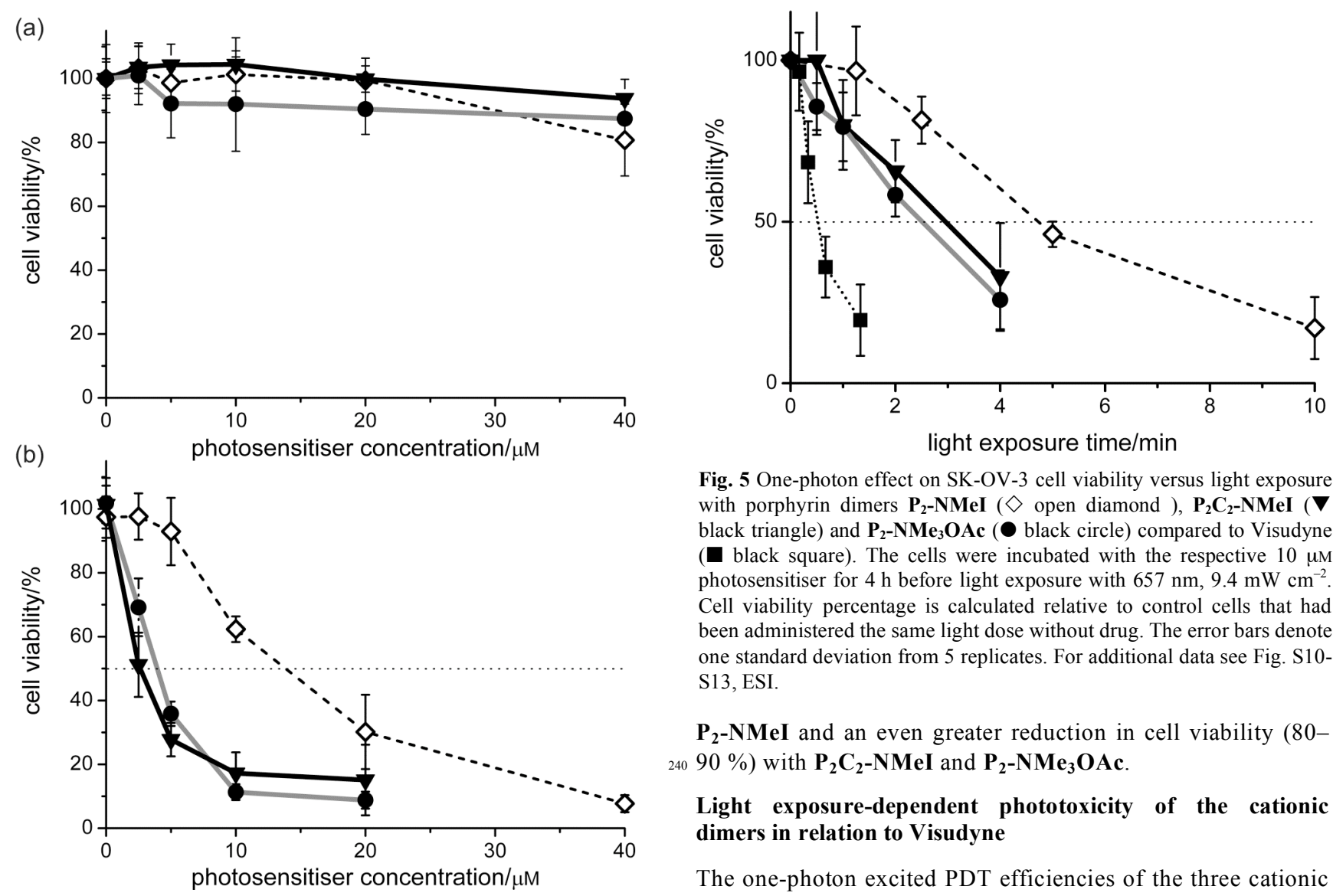

Fig. 5 One-photon effect on SK-OV-3 cell viability versus light exposure with porphyrin dimers $\mathbf{P}_{2}$-NMeI $\left(\diamond\right.$ open diamond ), $\mathbf{P}_{2} \mathbf{C}_{2}$-NMeI $(\boldsymbol{\nabla}$ black triangle) and $\mathbf{P}_{2}-\mathbf{N M e} \mathbf{P A A c}_{3} \mathbf{O}$ black circle) compared to Visudyne ( black square). The cells were incubated with the respective $10 \mu \mathrm{M}$ photosensitiser for $4 \mathrm{~h}$ before light exposure with $657 \mathrm{~nm}, 9.4 \mathrm{~mW} \mathrm{~cm}^{-2}$. Cell viability percentage is calculated relative to control cells that had been administered the same light dose without drug. The error bars denote one standard deviation from 5 replicates. For additional data see Fig. S10S13, ESI.

$\mathbf{P}_{2}$-NMeI and an even greater reduction in cell viability $(80$ $24090 \%$ ) with $\mathbf{P}_{\mathbf{2}} \mathbf{C}_{\mathbf{2}}$-NMeI and $\mathbf{P}_{\mathbf{2}}$-NMe $\mathbf{N} \mathbf{O A c}$.

Light exposure-dependent phototoxicity of the cationic dimers in relation to Visudyne

The one-photon excited PDT efficiencies of the three cationic dimers were compared to Visudyne by measuring the light

Fig. 4 (a) Dark-toxicity and (b) phototoxicity of porphyrin dimers $\mathbf{P}_{2}$-NMeI $(\diamond$ open diamond $), \mathbf{P}_{2} \mathbf{C}_{2}$-NMeI ( $\boldsymbol{\nabla}$ black triangle) and $\mathbf{P}_{2}-$ $\mathrm{NMe}_{3} \mathbf{O A c}(-$ black circle) towards SK-OV-3 cells as a function of photosensitiser concentration. The cells were incubated with the respective photosensitiser for $18 \mathrm{~h}$ and if required, the cells were exposed to a $657 \mathrm{~nm}, 9.4 \mathrm{~mW} \mathrm{~cm}{ }^{-2}, 4$ min light dose $\left(2.3 \mathrm{~J} \mathrm{~cm}^{-2}\right)$. The cell viability is calculated relative to control cells that had been administered the same light dose without a drug. The error bars denote one standard deviation from 5 replicates. For additional data see Fig. S7-S9, ESI.

220

\section{Concentration-dependent phototoxicity of the cationic dimers}

The dark-toxicity and phototoxicity of the cationic porphyrin dimers were investigated as a function of the photosensitiser concentration. At concentrations below $20 \mu \mathrm{M}$ no significant

225 dark-toxicity was observed for any of the drugs after 18 hours incubation, as shown in Fig. $4 \mathrm{a}$, which is encouraging given this long incubation time. At $40 \mu \mathrm{M}$ concentration, there may be slight dark-toxicity, although the cell viability remains above $80 \%$ for all of the photosensitisers. In Fig. $4 \mathrm{~b}$ the cell

230 survival is reported using the same 18 hour incubation period followed by 4 minutes light exposure. From this graph the photosensitiser concentration required to kill $50 \%$ of the cells, $L D_{50}$ (drug), may be estimated. The $L D_{50}$ (drug) values for $\mathbf{P}_{\mathbf{2}} \mathbf{C}_{\mathbf{2}}-\mathbf{N M e I}$ and $\mathbf{P}_{\mathbf{2}}-\mathbf{N M e} \mathbf{N A}_{\mathbf{3}} \mathbf{O A c}$ are similar, $2.8 \pm 0.7 \mu \mathrm{M}$ 235 and $3.9 \pm 0.3 \mu \mathrm{M}$ respectively, whereas $\mathbf{P}_{\mathbf{2}}$-NMeI requires a substantially higher concentration of $13.7 \pm 1.5 \mu \mathrm{M}$. A concentration of $10 \mu \mathrm{M}$ was used for the subsequent in vitro PDT experiments since this gave around $40 \%$ cell kill with

exposure time required to kill $50 \%$ of the cells, using identical photosensitiser concentrations $(10 \mu \mathrm{M})$ and incubation times (4 hours). From preceding studies it has been established that Visudyne is rapidly taken up by cells and only requires an incubation time of around 2.5 hours to maximise 250 its intracellular concentration. ${ }^{46}$ Thus, an incubation time of 4 hours was chosen as a compromise between the optimal incubation times for all the photosensitisers. When using the fixed incubation conditions of $10 \mu \mathrm{M}$ for 4 hours, we found that the irradiation time required to kill $50 \%$ of the cells, ${ }_{255} L D_{50}$ (light), was $0.5 \pm 0.1$ minutes for Visudyne, $2.5 \pm 0.3$ minutes for $\mathbf{P}_{\mathbf{2}}$-NMe $\mathbf{N} \mathbf{O A c}, 3.1 \pm 0.8$ minutes for $\mathbf{P}_{\mathbf{2}} \mathbf{C}_{\mathbf{2}}$-NMeI and $4.7 \pm 0.2$ minutes for $\mathbf{P}_{\mathbf{2}}$-NMeI (Fig. 5). Hence, the irradiation time required to kill half the cells was about 5 to 6 times greater with $\mathbf{P}_{\mathbf{2}} \mathbf{C}_{\mathbf{2}}$-NMeI and $\mathbf{P}_{\mathbf{2}}-\mathbf{N} \mathbf{M} \mathbf{N}_{3} \mathbf{O A c}$ than with ${ }_{260}$ Visudyne and around 10 times larger with $\mathbf{P}_{2}$-NMeI. The somewhat extended irradiation time required for $\mathbf{P}_{2}$-NMeI reflects the finding that with 4 hours incubation the phototoxic effect of dimer $\mathbf{P}_{\mathbf{2}}$-NMeI is less than dimers $\mathbf{P}_{\mathbf{2}} \mathbf{C}_{\mathbf{2}}$-NMeI and $\mathbf{P}_{\mathbf{2}}-\mathbf{N M e}_{3} \mathbf{O A c}$, Fig. 3. With incubation times longer than 6 265 hours, all the dimers would be expected to show similar $L D_{50}$ (light) values.

\section{Optimised one-photon PDT efficiency of the porphyrin} dimers

270 Finally, a one-photon PDT experiment was performed under optimised conditions, using $10 \mu \mathrm{M}$ solution, incubated with 


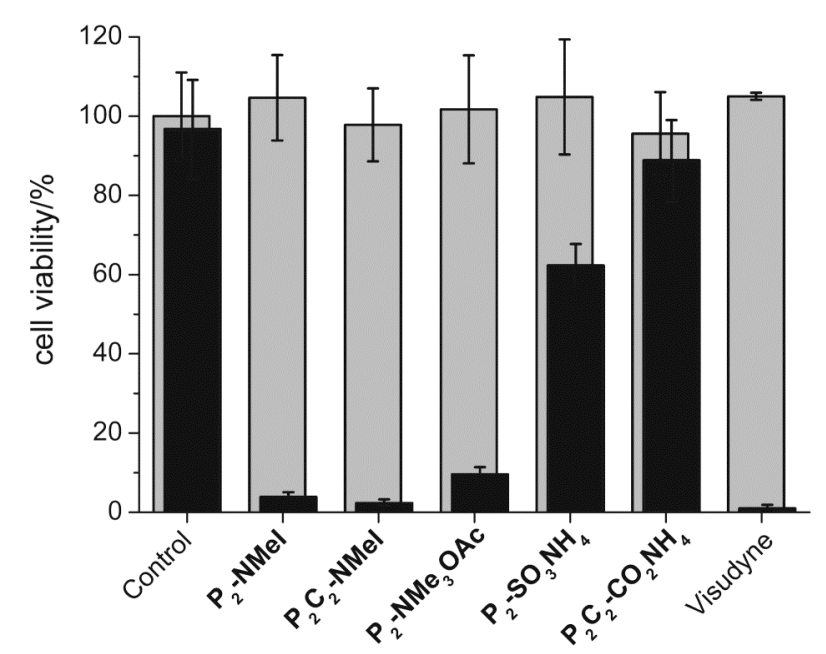

Fig. 6 One-photon effect on SK-OV-3 cell viability using the porphyrin dimer photosensitisers. The cells were incubated with $10 \mu \mathrm{M}$ of the respective photosensitiser for $6 \mathrm{~h}$ before light exposure. Dark controls in grey; light control: cells were exposed to a $657 \mathrm{~nm}, 9.4 \mathrm{~mW} \mathrm{~cm}^{-2}, 20 \mathrm{~min}$ light dose $\left(11 \mathrm{~J} \mathrm{~cm}^{-2}\right)$. The error bars denote one standard deviation from 5 replicates. For additional data see Fig. S14, ESI.

the SK-OV-3 cells for 6 hours prior to light exposure. Excellent PDT effects were achieved with all three cationic dimers with an irradiation time of 20 minutes at $657 \mathrm{~nm}$. As

275 can be seen from Fig. 6, cell survival rates are less than $5 \%$ for dimers $\mathbf{P}_{\mathbf{2}}$-NMeI and $\mathbf{P}_{\mathbf{2}} \mathbf{C}_{\mathbf{2}}$-NMeI and less than $10 \%$ for the dimer $\mathbf{P}_{\mathbf{2}}-\mathbf{N M e}_{\mathbf{3}} \mathbf{O A c}$. Using the same incubation and irradiation conditions, significantly smaller PDT effects were achieved with the anionic dimers, $\mathbf{P}_{2}-\mathbf{S O}_{3} \mathbf{N H}_{4}(62 \pm 5 \%)$ and

${ }_{280} \mathbf{P}_{\mathbf{2}} \mathbf{C}_{\mathbf{2}}-\mathbf{C O}_{\mathbf{2}} \mathbf{N H}_{\mathbf{4}} \quad(89 \pm 10 \%)$. While the commercial drug Visudyne shows close to $100 \%$ cell death under the same conditions.

As discussed earlier there are many factors which influence the PDT efficiency of a drug. The $657 \mathrm{~nm}$ extinction ${ }_{285}$ coefficients of the cationic dimers and Visudyne are summarised in Table 1, together with the corresponding $L D_{50}$ (drug) and $L D_{50}$ (light) values. If we account for the varying extinction coefficients of the photosensitisers at the excitation wavelength and include the results from the anionic 290 dimers, the phototherapeutic efficiencies increase in the order $\mathbf{P}_{2} \mathrm{C}_{2}-\mathrm{CO}_{2} \mathrm{NH}_{4}<\mathrm{P}_{2}-\mathrm{SO}_{3} \mathrm{NH}_{4}<\mathrm{P}_{2}-\mathrm{NMeI}<\mathrm{P}_{2}-\mathrm{NMe}_{3} \mathrm{OAc}<$

Table 1 Extinction coefficients and one-photon excited PDT efficiencies for cationic porphyrin dimers and the commercial drug Visudyne.

\begin{tabular}{|c|c|c|c|}
\hline Photosensitiser (PS) & $\begin{array}{c}\varepsilon \\
\left(\mathrm{M}^{-1} \mathrm{~cm}^{-1}\right)^{a}\end{array}$ & $\frac{L D_{50}(\text { drug }):}{\text { PS conc. }(\mu \mathrm{M})^{b}}$ & $\frac{L D_{50}(\text { light }): \text { Light }}{\text { exposure }(\min )^{c}}$ \\
\hline $\mathrm{P}_{2}$-NMeI & 36,000 & $13.7 \pm 1.5$ & $4.7 \pm 0.2$ \\
\hline $\mathrm{P}_{2} \mathrm{C}_{2}$-NMeI & 25,000 & $3.9 \pm 0.3$ & $2.5 \pm 0.3$ \\
\hline $\mathrm{P}_{2}-\mathrm{NMe}_{3} \mathrm{OAc}$ & 36,000 & $2.8 \pm 0.7$ & $3.1 \pm 0.8$ \\
\hline Visudyne & 4500 & $1.0 \pm 0.1$ & $0.5 \pm 0.1$ \\
\hline
\end{tabular}

${ }^{a}$ Measured in DMF at $657 \mathrm{~nm}$.

${ }^{b} 18 \mathrm{~h}$ incubation with the photosensitiser, 4 min irradiation at $657 \mathrm{~nm}$. ${ }^{c} 4 \mathrm{~h}$ incubation with $10 \mu \mathrm{M}$ of the photosensitiser, irradiation at $657 \mathrm{~nm}$.
$\mathbf{P}_{\mathbf{2}} \mathbf{C}_{\mathbf{2}}$-NMeI $<$ Visudyne. The considerable research that has been undertaken in designing and formulating the commercial drug is evident from its excellent one-photon PDT efficiency. ${ }_{295}$ Compared to the other dimers in this study $\mathbf{P}_{\mathbf{2}} \mathbf{C}_{\mathbf{2}}$-NMeI showed the lowest dark-toxicity and greatest PDT efficiency, and its smaller extinction coefficient at $657 \mathrm{~nm}$ results in a better $L D_{50}($ light $)$ and similar $L D_{50}$ (drug) to that of $\mathbf{P}_{2}-\mathrm{NMe}_{3} \mathbf{O A c}$. From incubation studies in SK-OV-3 cells ${ }_{300} \mathbf{P}_{2} \mathbf{C}_{2}$-NMeI produces a $90 \pm 5 \%$ cell kill with 4 hours incubation $\left(2260 \mathrm{~mJ} \mathrm{~cm}^{-2}\right)$, which is comparable to the effect of Visudyne. The high singlet oxygen yield of $\mathbf{P}_{\mathbf{2}} \mathbf{C}_{\mathbf{2}}$-NMeI $\left(\phi_{\Delta}=0.6\right.$ in methanol) in combination with the highest measured (for our porphyrin dimers) two-photon cross-section $305(\delta=17,000 \mathrm{GM} \text { at } 916 \mathrm{~nm})^{36}$ make this drug the most promising two-photon excited PDT sensitiser from this family. Therefore, $\mathbf{P}_{\mathbf{2}} \mathbf{C}_{\mathbf{2}}$-NMeI was selected for in vitro twophoton PDT studies.

\section{Two-photon excited PDT efficiency of porphyrin dimer $\mathbf{P}_{2} \mathbf{C}_{2^{-}}$ NMeI}

One of the key benefits of two-photon excitation is the highly targeted treatment that can be achieved. However, since the excitation volume is so small (ca $1-1000 \mu \mathrm{m}^{3}$ ) it would be 315 difficult to quantify the in vitro phototoxic effect by the same colourimetric method used for the one-photon cell kill experiments. The two-photon induced therapeutic effect was instead evaluated using a procedure developed by Wilson and co-workers. ${ }^{19}$ This technique employs a confocal laser 320 scanning microscope to irradiate and measure a two-photon PDT effect using a fluorescent dye-based cell-permeability assay. $^{46}$

Firstly, we sought to confirm that the PDT effect of $\mathbf{P}_{2} \mathbf{C}_{2}$-NMeI in this experiment is really due to a two-photon 325 absorption process, and not, for example, due to activation of the long-wavelength tail of the photosensitiser one-photon absorption. This can be demonstrated by the characteristic quadratic dependence of the light dose, $L D_{50}($ light), on the irradiation intensity. Hence, a monolayer of SK-OV-3 cells 330 was incubated for 18 hours with $\mathbf{P}_{\mathbf{2}} \mathbf{C}_{\mathbf{2}}$-NMeI and discrete areas $(230 \times 230 \mu \mathrm{m})$ were irradiated with varying doses of $920 \mathrm{~nm}$ light ( $300 \mathrm{fs}, 90 \mathrm{MHz}$ ) using a 40×, 1.2 NA objective. The cell-viability was determined 5 hours after irradiation using the cell-permeable DNA stain, Hoechst 33258 and the 335 dead-cell indicator Sytox orange. Examples of confocal images of individual cell areas after two-photon excited PDT are displayed in Fig. 7, showing increasing degrees of cell death at longer exposure times.

As in the case of one-photon PDT, the $L D_{50}$ (light) for ${ }_{340} \mathbf{P}_{\mathbf{2}} \mathbf{C}_{\mathbf{2}}$-NMeI was calculated by plotting the cell viability as a function of exposure time (number of scans) as seen in Fig. 8a. The $\log \left[L D_{50}(\right.$ light $\left.)\right]$ is plotted against $\log \left[\right.$ laser power $\left.{ }^{-1}\right]$ and the gradient of a linear fit to these points is $2.0 \pm 0.2$, confirming two-photon activation of $\mathbf{P}_{\mathbf{2}} \mathbf{C}_{\mathbf{2}}-\mathbf{N M e I}$ at $920 \mathrm{~nm}$, ${ }_{345}$ Fig. 8b. 

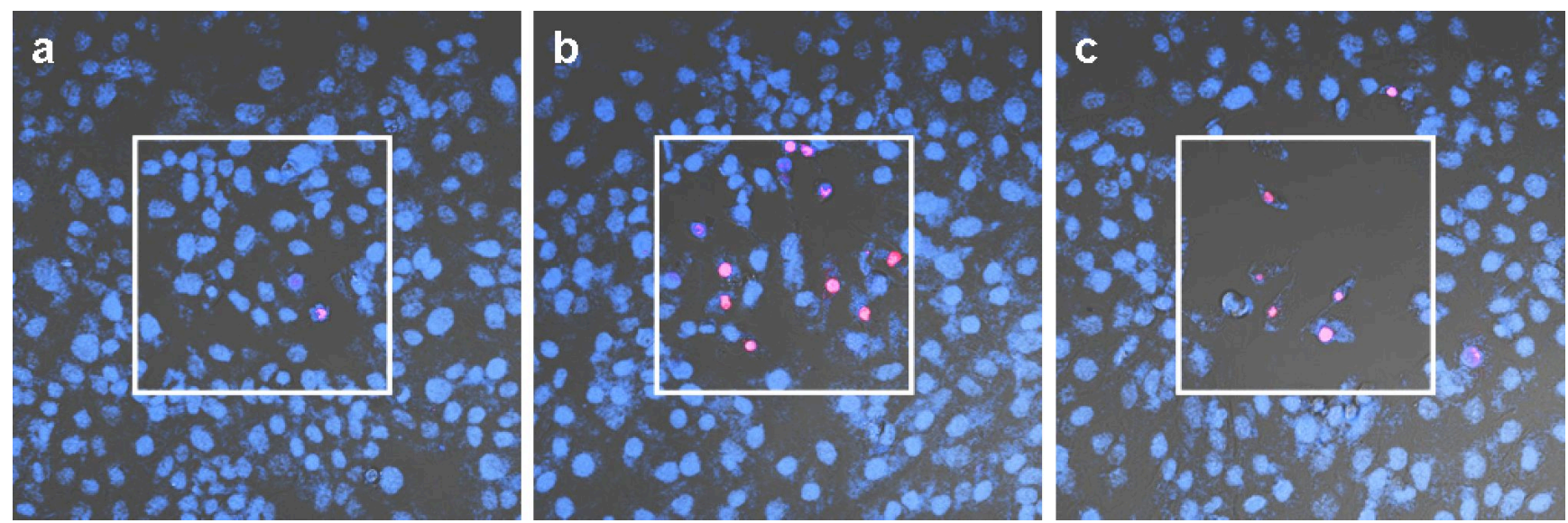

Fig. 7 Example confocal images of two-photon excited PDT using porphyrin dimer sensitiser $\mathbf{P}_{2} \mathbf{C}_{2}$-NMeI on SK-OV-3 cells; only the central square region, indicated by the white box $(230 \times 230 \mu \mathrm{m})$, was irradiated. The combined transmission and fluorescence images are shown, all nuclei are stained with Hoechst 33258 (blue) and cells with compromised plasma membranes are co-stained with Sytox orange (magenta). The central region was irradiated with $920 \mathrm{~nm}$ (300 fs, $90 \mathrm{MHz}, 6.8 \mathrm{~mW}$ ): (a) 60 scans, (b) 100 scans and (c) 320 scans.

The one- and two-photon PDT efficiencies of porphyrin dimer $\mathbf{P}_{\mathbf{2}} \mathbf{C}_{\mathbf{2}}$-NMeI and Visudyne are compared in Fig. 9. As presented above, when using continuous wave irradiation (657 $350 \mathrm{~nm}, 9.4 \mathrm{~mW} \mathrm{~cm}{ }^{-2}$ ), 18 hours incubation and $10 \mu \mathrm{M}$ concentration, the commercial drug is substantially more phototoxic than $\mathbf{P}_{\mathbf{2}} \mathbf{C}_{\mathbf{2}}$-NMeI, even though the extinction coefficient of Visudyne is considerably lower at the irradiation wavelength, $4500 \mathrm{M}^{-1} \mathrm{~cm}^{-1}$ compared to $25,000 \mathrm{M}^{-1}$ $355 \mathrm{~cm}^{-1}$ for the dimer, Fig. 9a. The light exposure required to kill $50 \%$ of the cells was $44 \mathrm{~s}$ for Visudyne compared to $180 \mathrm{~s}$ for the dimer. Using the same photosensitiser, concentration and incubation conditions the cells were excited by two-photon absorption using $920 \mathrm{~nm}$ light ( $300 \mathrm{fs}, 90 \mathrm{MHz}, 3.9 \mathrm{~mW}$ ). The 360 respective $L D_{50}$ (light) values were reversed under these excitation conditions, with $\mathbf{P}_{\mathbf{2}} \mathbf{C}_{\mathbf{2}}$-NMeI requiring a shorter irradiation time of $110 \pm 30 \mathrm{~s}$, compared to $180 \pm 30 \mathrm{~s}$ for Visudyne, see Fig. 9b. The larger TPA cross-section of $\mathbf{P}_{2} \mathbf{C}_{2}$-NMeI $(16,000 \mathrm{GM}$ compared to $46 \mathrm{GM}$ for Visudyne at ${ }_{365} 920 \mathrm{~nm}$ ) compensates in part for its lower photodynamic efficiency, such that the dimer is a better two-photon photosensitiser than Visudyne. From the ratios of the onephoton extinction coefficients, one-photon PDT efficacies and two-photon cross sections, one would expect $\mathbf{P}_{\mathbf{2}} \mathbf{C}_{\mathbf{2}}$-NMeI to

370 be about 15 times more effective than Visudyne for twophoton PDT. ${ }^{46}$ However the two-photon efficacy ratio measured here is only 1.6. This must reflect the different assay conditions used in the two-photon and one-photon PDT experiments. $\quad \mathbf{P}_{\mathbf{2}} \mathbf{C}_{\mathbf{2}}$-NMeI appears to be relatively less 375 phototoxic towards the closely packed monolayers of cells used in two-photon PDT, compared to the sparsely dispersed cells in the one-photon assay. Another difference between the assay conditions is the longer time ( 48 hours vs. 5 hours) between light-exposure and determination of cell-viability in 380 the one-photon assay, which makes this procedure more sensitive to apoptic cell death.

\section{Conclusions}

The phototoxic properties of a new series of conjugated porphyrin dimers with high two-photon absorption cross-
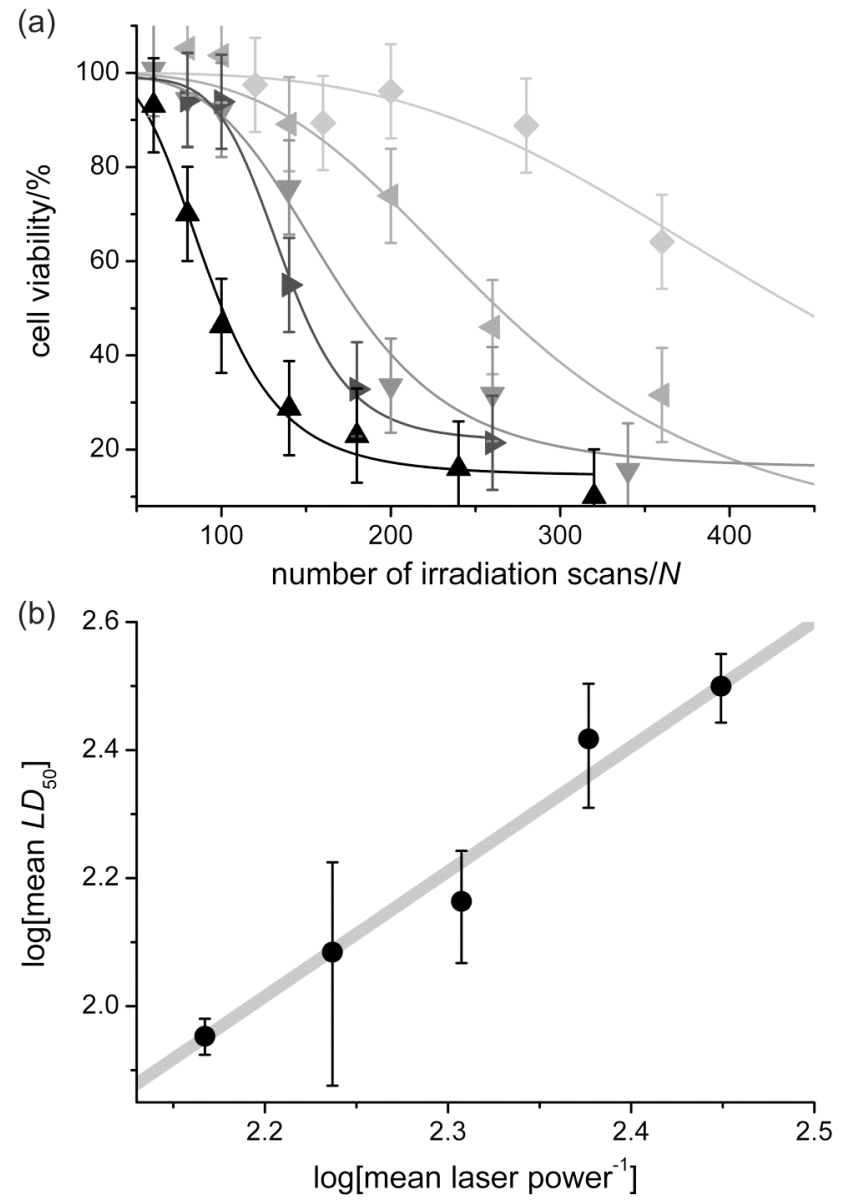

Fig. 8 (a) Dependence of the in vitro two-photon excited PDT effect of $\mathbf{P}_{2} \mathbf{C}_{2}$-NMeI on the irradiating laser power. Example series of in vitro cell viability curves produced using irradiation at $920 \mathrm{~nm}, 300 \mathrm{fs}, 90 \mathrm{MHz}$ and 5 discrete laser powers: $\boldsymbol{\Delta} 6.8,>5.8, \nabla 4.9,<4.2$, and $>3.6 \mathrm{~mW}$. (b) The PDT light dose (number of scans) required to kill $50 \%$ of the cells ( $L D_{50}$ light) is determined from the cell viability curves in (a) and the $\log \left[L D_{50}\right]$ is plotted against the $\log \left[\right.$ laser power $\left.{ }^{-1}\right]$. The error bars in (a) represent the estimated $10 \%$ error in determining cell viability by fluorescent staining and in (b) denote one standard error. 

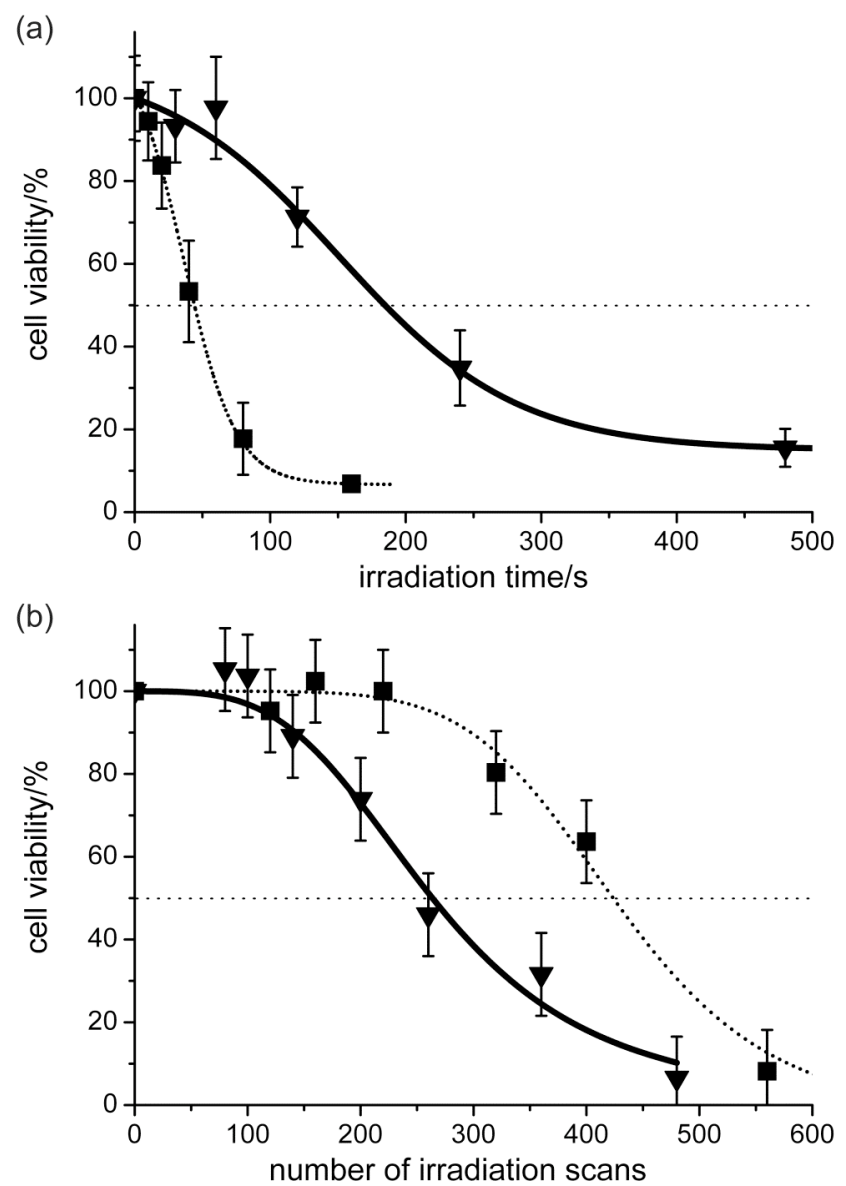

Fig. 9 In vitro (a) one-photon $\left(657 \mathrm{~nm}, 9.4 \mathrm{~mW} \mathrm{~cm}^{-2}\right.$ continuous wave) and (b) two-photon $(920 \mathrm{~nm}, 300 \mathrm{fs}, 90 \mathrm{MHz}, 4.2 \mathrm{~mW})$ PDT effect of porphyrin dimer $\mathbf{P}_{2} \mathbf{C}_{2}-\mathbf{N M e I}$ ( $\boldsymbol{\nabla}$ black triangle) compared to Visudyne ( black square) using SK-OV-3 cells. The error bars in (a) denote one standard deviation from 5 replicates and in (b) represent the estimated $10 \%$ error in determining cell viability by fluorescent staining.

385 sections $(8000-17,000 \text { GM) })^{36}$ have been explored and quantified. All five dimers show uptake by SK-OV-3 cells and possess high singlet oxygen yields $\left(\phi_{\Delta}=0.5-0.9\right.$ in methanol). ${ }^{36}$ Although the anionic dimers, $\mathbf{P}_{2}-\mathbf{S O}_{3} \mathbf{N H}_{4}$ and $\mathbf{P}_{2} \mathbf{C}_{2}-\mathbf{C O}_{2} \mathbf{N H}_{4}$, demonstrate a significant PDT effect, their 390 cationic counterparts, $\quad \mathbf{P}_{2} \mathbf{C}_{2}$-NMeI, $\quad \mathbf{P}_{2}$-NMe $\mathbf{N}_{3} \mathbf{O A c}$ and $\mathbf{P}_{2}$-NMeI, exhibit far greater one-photon PDT efficiencies. None of the dimers were measurably toxic in the absence of light up to $20 \mu \mathrm{M}$ concentrations. The cationic dimers treated with a short (4 min.) light dose at $657 \mathrm{~nm}\left(9.4 \mathrm{~mW} \mathrm{~cm}^{-2}, 2.3 \mathrm{~J}\right.$ $395 \mathrm{~cm}^{-2}$ ) show one-photon excited PDT efficiencies that are comparable to the commercial drug Visudyne; the irradiation time required to kill $50 \%$ of the cells was approximately 5 times longer for $\mathbf{P}_{2} \mathbf{C}_{2}$-NMeI and $\mathbf{P}_{2}-\mathbf{N M e}_{3} \mathbf{O A c}$ relative to Visudyne and around 10 times longer for $\mathbf{P}_{2}$-NMeI.

$400 \quad \mathbf{P}_{2} \mathbf{C}_{\mathbf{2}}$-NMeI was selected as the best photosensitiser for two-photon PDT testing. The two-photon induced PDT effect of the porphyrin dimer was shown to be proportional to the square of the irradiating power using excitation at $920 \mathrm{~nm}$ (300 fs, $90 \mathrm{MHz}, 3.6-6.8 \mathrm{~mW}$ ) confirming two-photon 405 activation. Under two-photon irradiation $\mathbf{P}_{\mathbf{2}} \mathbf{C}_{\mathbf{2}}$-NMeI was found to be superior to the commercial drug Visudyne: to kill $50 \%$ of the cells by two-photon activation, $\mathbf{P}_{\mathbf{2}} \mathbf{C}_{2}$-NMeI required half the light dose needed for Visudyne. In keeping with these results, $\mathbf{P}_{\mathbf{2}} \mathbf{C}_{\mathbf{2}}$-NMeI was recently found to be more 410 effective than Visudyne during in vivo two-photon PDT blood vessel closure experiments. ${ }^{34}$

The red-shifted absorption spectra and appreciable singlet oxygen quantum yields of the porphyrin dimers make them ideal candidates for long wavelength one-photon excited PDT, 415 thereby aiding deeper treatment depths. However, it is their extremely large TPA cross-sections that offer the greatest benefits. The cationic dimers are promising photosensitisers for two-photon induced photodynamic therapy, a new treatment modality which would allow the precise targeting of ${ }_{420}$ diseased tissues. The higher two-photon cross sections of these new drugs should make them about 350-times more effective than Visudyne for two-photon PDT, but further optimisation will be required to fully realise this advantage. Optimisation of the formulation and use of delivery vehicles, ${ }_{425}$ such as liposomes, may improve the pharmacokinetics and microdistribution behaviour of these two-photon drugs, as has already been achieved with Visudyne.

\section{Experimental}

\section{Materials and methods}

\section{${ }_{430}$ Cell culture}

SK-OV-3 (human ovarian adenocarcinoma, ECACC) cells were grown in phenol red free Dulbecco's Modified Eagle's Medium (DMEM, Gibco) supplemented with $2 \mathrm{~mm}$ $L$-glutamine, penicillin $\left(100 \mathrm{U} \mathrm{mL}^{-1}\right)$, streptomycin $(100 \mu \mathrm{g}$ ${ }_{435} \mathrm{~mL}^{-1}$ ) and $10 \%$ fetal bovine serum (FBS, Sigma). The cells were maintained at $37{ }^{\circ} \mathrm{C}$ in a humidified $5 \% \quad \mathrm{CO}_{2}$ atmosphere.

\section{Photosensitisers and delivery conditions}

${ }_{440}$ The synthesis of the porphyrin dimers $\mathbf{P}_{2}-\mathbf{N M e}_{3} \mathbf{O A c}$, $\mathbf{P}_{2}$-NMeI, $\mathbf{P}_{2} \mathbf{C}_{2}$-NMeI, $\mathbf{P}_{2}-\mathbf{S O}_{3} \mathbf{N H}_{4}$ and $\mathbf{P}_{\mathbf{2}} \mathbf{C}_{2}-\mathbf{C O}_{\mathbf{2}} \mathbf{N H}_{4}$ was described previously. ${ }^{35}$ The porphyrin dimers were dissolved in DMSO to form $1.0 \mathrm{mM}$ stock solutions, the compounds were diluted to their required concentrations in DMEM ${ }_{445}$ immediately before they were administered to the cells. For the concentration experiments, 100 -fold stock solutions were produced in DMSO, such that the DMSO content of the incubation solutions was always $1 \%$. Visudyne $(0.95 \mathrm{mg})$ was dissolved in DMEM culture media $(2.4 \mathrm{~mL})$ to give $10 \mu \mathrm{M}$ of 450 the active photosensitiser and this solution was vortexed for 3 minutes before it was added to the cells.

\section{One-photon excited PDT}

Testing of the PDT efficiency of the porphyrin dimers was ${ }_{455}$ performed in microwell plates using the CellTiter $96^{\circledR}$ AQueous one solution cell proliferation assay (Promega) to determine cell viability. SK-OV-3 cells were seeded in flatbottomed 96 -well plates (Nunc, with a $0.34 \mathrm{~cm}^{2}$ growth area) at a density of 1250 cells per well in $100 \mu \mathrm{L}$ of culture media. ${ }_{460}$ The cells were irradiated $26 \mathrm{~h}$ after seeding. At the required time before the light dose, the media on the cells was replaced with the photosensitiser solution. The plates were shielded from light during and after incubation. Following incubation the wells that required light exposure were irradiated with 
${ }_{465} 657 \mathrm{~nm}\left(9.4 \mathrm{~mW} \mathrm{~cm}{ }^{-2}\right.$, Dotlight GbR, Germany). Following light exposure the cells were washed three times with $100 \mu \mathrm{L}$ of fresh media and incubated in $100 \mu \mathrm{L}$ of media for $42 \mathrm{~h}$. The cell viability was then determined according to the manufacturers instructions. The assay absorbance 470 measurements were carried out using a plate reader (POLARstar OPTIMA, BMG Labtech) at $490 \mathrm{~nm}$ and the absorbance was directly proportional to the number of living cells over the range of cell concentrations used. It was necessary to record a background absorbance reading of the

475 media, by adding the assay to five wells that did not contain cells. The average of the background readings was subtracted from the average absorbance of each replicate group before further data manipulation. Each quoted cell viability value is the average from a minimum of 5 replicates, and the reported 480 error bars represent \pm 1 standard deviation from the mean. Each experiment was repeated a minimum of three times to confirm reproducibility, these replicates are given in the ESI, Figures S2-S14.

\section{Two-photon excited PDT}

SK-OV-3 cells were seeded in 2-well coverglass chambers (Nunc) at a density of $1.3 \times 10^{5}$ cells per well in $2 \mathrm{~mL}$ of media. The cells were left to grow to confluence over 3 days, such that a uniform monolayer was produced. The cells were

490 incubated for $18 \mathrm{~h}$ prior to irradiation with $10 \mu \mathrm{M}$ of the active photosensitiser. The monolayer was irradiated using a confocal laser scanning microscope (LSM 510 Meta NLO, Carl Zeiss) coupled to an argon-ion laser (514 nm) and a Ti:sapphire laser (Cameleon, Coherent) tunable from 720 to $495960 \mathrm{~nm}$, with $300 \mathrm{fs}$ pulse duration at the sample and $90 \mathrm{MHz}$ repetition rate. A $40 \times$, numerical aperture (NA) 1.2, air objective was used and the focused laser light scanned the sample in a raster pattern $512 \times 512$ pixels, $230 \times 230 \mu \mathrm{m}$, with a dwell time of $1.6 \mu \mathrm{s}$ per pixel. The cell viability was 500 determined $5 \mathrm{~h}$ after irradiation by staining for $1 \mathrm{~h}$ with $10 \mu \mathrm{g}$ $\mathrm{mL}^{-1}$ Hoechst 33258 and $2.5 \mu \mathrm{M}$ of Sytox Orange (Invitrogen), as described previously. ${ }^{46}$

\section{Acknowledgements}

We gratefully acknowledge financial support from the EPSRC 505 and the Canadian Institute for Photonic Innovations. E.D. thanks the Wenner-Gren Foundations, the Hans Werthén Foundation and the Royal Swedish Academy of Sciences for individual support. This work was partially supported by the European Union in the form of a Marie Curie individual ${ }_{510}$ Fellowship to M.B. under the contract MEIF-CT2007-041522. Alan Roper and Peter Williams are gratefully acknowledged for building the LED array. M.K. was supported by a Banting and Best Canada Graduate Scholarship.

\section{References}

5151 R. Bonnet, Chem. Soc. Rev., 1995, 19-33.

2 I. J. MacDonald and T. J. Dougherty, J. Porphyrins Phthalocyanines, 2001, 5, 105-129.

3 S. B. Brown, E. A. Brown and I. Walker, Lancet Oncol., 2004, 5, $497-$ 508.

5204 R. R. Allison, G. H. Downie, R. Cuenca, X.-H. Hu, C. J. H. Childs and C. H. Sibata, Photodiagn. Photodyn. Therap., 2004, 1, 27-42.
5 S. Verma, G. M. Watt, Z. Mai and T. Hasan, Photochem. Photobiol., 2007, 83, 996-1005.

6 E. S. Nyman and P. H. Hynninen, J. Photochem. Photobiol., B, 2004, 73, 1-28.

7 D. Kessel, Photodiagn. Photodyn. Therap., 2004, 1, 3-7.

8 E. D. Sternberg, D. Dolphin and C. Bruckner, Tetrahedron, 1998, 54, 4151-4202.

9 M. Ochsner, J. Photochem. Photobiol., B, 1996, 32, 3-9.

53010 J. Eichler, J. Knof and H. Lenz, Radiat. Environ. Biophys., 1977, 14, 239-242.

11 S. Wan, J. A. Parrish, R. R. Anderson and M. Madden, Photochem. Photobiol., 1981, 34, 679-681.

12 S. Stolik, J. A. Delgado, A. Perez and L. Anasagasti, J. Photochem. Photobiol., B, 2000, 57, 90-93.

13 R. Weissleder, Nat. Biotechnol., 2001, 19, 316-317.

14 R. W. Boyle and D. Dolphin, Photochem. Photobiol., 1996, 64, 469485.

15 J. D. Bhawalkar, G. S. He and P. N. Prasad, Rep. Prog. Phys., 1996, $540 \quad$ 59, 1041-1070.

16 W. R. Zipfel, R. M. Williams and W. W. Webb, Nat. Biotechnol., 2003, 21, 1369-1377.

17 C. Xu, R. M. Williams, W. Zipfel and W. W. Webb, Bioimaging, 1996, 4, 198-207.

54518 K. S. Samkoe, A. A. Clancy, A. Karotki, B. C. Wilson and D. T. Cramb, J. Biomed. Opt., 2007, 12, 034025/034021-034025/034014.

19 A. Karotki, M. Khurana, J. R. Lepock and B. C. Wilson, Photochem. Photobiol., 2006, 82, 443-452.

20 S. Kawata, H.-B. Sun, T. Tanaka and K. Takada, Nature, 2001, 412, 697-698.

21 C. Xu, W. Zipfel, J. B. Shear, R. M. Williams and W. W. Webb, Proc. Natl. Acad. Sci. USA, 1996, 93, 10763-10768.

22 M. Drobizhev, Y. Stepanenko, Y. Dzenis, A. Karotki, A. Rebane, P. N. Taylor and H. L. Anderson, J. Phys. Chem. B, 2005, 109, 72237236.

23 M. K. Kuimova, M. Hoffmann, M. U. Winters, M. Eng, M. Balaz, I. P. Clark, H. A. Collins, S. M. Tavender, C. J. Wilson, B. Albinsson, H. L. Anderson, A. W. Parker and D. Phillips, Photochem. Photobiol. Sci., 2007, 6, 675-682.

56024 M. Albota, D. Beljonne, J.-L. Bredas, J. E. Ehrlich, J.-Y. Fu, A. A. Heikal, S. E. Hess, T. Kogej, M. D. Levin, S. R. Marder, D. McCordMaughon, J. W. Perry, H. Rockel, M. Rumi, G. Subramaniam, W. W. Webb, X.-L. Wu and C. Xu, Science, 1998, 281, 1653-1656.

25 M. Drobizhev, F. Meng, A. Rebane, Y. Stepanenko, E. Nickel and C. W. Spangler, J. Phys. Chem. B, 2006, 110, 9802-9814.

26 P. C. Ray and Z. Sainudeen, J. Phys. Chem. A, 2006, 110, 1234212347.

27 A. Karotki, M. Kruk, M. Drobizhev, A. Rebane, E. Nickel and C. W. Spangler, IEEE J. Sel. Top. Quantum Electron., 2001, 7, 971-975.

57028 P. Lenz, Photochem. Photobiol., 1995, 62, 333-338.

29 A. Karotki, M. Khurana, S. K. Bisland, E. H. Moriyama, E. R. Simpson, M. C. W. Campbell, H. Collins, H. L. Anderson, D. T. Cramb and B. C. Wilson, Proc. SPIE, 2007, 6427, 64270R/64271$64270 \mathrm{R} / 64278$.

57530 W. G. Fisher, W. P. Partridge, Jr., C. Dees and E. A. Wachter, Photochem. Photobiol., 1997, 66, 141-155.

31 K. Ogawa, H. Hasegawa, Y. Inaba, Y. Kobuke, H. Inouye, Y. Kanemitsu, E. Kohno, T. Hirano, S.-i. Ogura and I. Okura, J. Med. Chem., 2006, 49, 2276-2283.

58032 S. Kim, T. Y. Ohulchanskyy, H. E. Pudavar, R. K. Pandey and P. N. Prasad, J. Am. Chem. Soc., 2007, 129, 2669-2675.

33 J. Arnbjerg, A. Jimenez-Banzo, M. J. Paterson, S. Nonell, J. I. Borrell, O. Christiansen and P. R. Ogilby, J. Am. Chem. Soc., 2007, 129, 51885199.

58534 H. A. Collins, M. Khurana, E. H. Moriyama, A. Mariampillai, E. Dahlstedt, M. Balaz, M. K. Kuimova, D. Phillips, M. Drobizhev, A. Rebane, B. C. Wilson and H. L. Anderson, Nature Photonics, 2008, 2, 420.

35 M. Balaz, H. A. Collins, E. Dahlstedt and H. L. Anderson, Org. Biomol. Chem., 2008, submitted.

36 M. K. Kuimova, H. A. Collins, M. Balaz, E. Dahlstedt, J. A. Levitt, N. Sergent, K. Suhling, M. Drobizhev, A. Rebane, H. L. Anderson and D. Phillips, Org. Biomol. Chem., 2008, submitted. 
37 B. Aveline, T. Hasan and R. W. Redmond, Photochem. Photobiol., 1994, 59, 328-335.

38 S. W. Young, K. W. Woodburn, M. Wright, T. D. Mody, Q. Fan, J. L. Sessler, W. C. Dow and R. A. Miller, Photochem. Photobiol., 1996, 63, 892-897.

39 Q. Chen, Z. Huang, D. Luck, J. Beckers, P.-H. Brun, B. C. Wilson, A.

600 Scherz, Y. Salomon and F. W. Hetzel, Photochem. Photobiol., 2002, 76, 438-445.

40 L. Brancaleon and H. Moseley, Lasers Med. Sci., 2002, 17, 173-186.

41 H. Kolarova, J. Mosinger, R. Lenobel, K. Kejlova, D. Jirova and M. Strnad, Toxicol. in Vitro, 2003, 17, 775-778.
60542 X. Chen, L. Hui, D. A. Foster and C. M. Drain, Biochemistry, 2004, 43, 10918-10929.

43 X. Ding, Q. Xu, F. Liu, P. Zhou, Y. Gu, J. Zeng, J. An, W. Dai and X. Li, Cancer Lett., 2004, 216, 43-54.

44 V. I. Danilov, J. J. P. Stewart, A. Les and J. L. Alderfer, Chem. Phys. Lett., 2000, 328, 75-82.

45 M. Ichihashi, M. Ueda, A. Budiyanto, T. Bito, M. Oka, M. Fukunaga, K. Tsuru and T. Horikawa, Toxicology, 2003, 189, 21-39.

46 M. Khurana, H. A. Collins, A. Karotki, H. L. Anderson, D. T. Cramb and B. C. Wilson, Photochem. Photobiol., 2007, 83, 1441-1448. 